and in the third ance, the starnum aloo. I hare ley great tres npon the neceesity of dividing the spine, because in al the Inglich books on midwifery which are in common ves this part of the operation is altogether omitted.

Zfter evisceration and division of the spine, the extraction of the child's body is also to be made in imitation of the mechanism of spontaneous expulsion. The hook is to be fixed into the lower part of the spine, and the lower part of the body to be drawn down into the hollow of the sacrum, and through the os externum, behind the upper part of the thorax and the presenting arm. This part of the operation does not usually present much difficulty.

Although embryotony in transverse presentations is a proceeding which must be very repugnant to the feelings of the accoucheur, and one which he ought not to undertake without a consultation, $y$ et it does not involve the same amount of responsibility as craniotomy. In arm presentations, when the waters have long escaped, and the uterus has contracted very closely around the child, the great pressure upon the cord will nearly always destroy the life of the child. In all such cases of unusual difficilty which have occurred to myself, and in which I hare managed to turn, the child has been still-born; and, I have no doubt, from this cause. So that if the accoucheur can succeed in turning, he will rarely be able to save the life of the child. Still, however, if he can turn without violence, and without unduly risking the safety of the mother, it is far better to do so than to perform embryotomy. But, if he cannot do so without great force, it is far preferable at once to perform embryotomy, which is a tolerably safe operation for the mother, than to push the hand into the uterus, in order to turn at all hazards, with a certainty of bringing into the world a dead child, and a great probability of causing the death of the mother.

Bristol, Octuber 1855.

\section{ON A NEW FORM OF ARTIFICIAL MEMBRANA TYMPANI.}

By THOMAS WESTROPP, Esq.

Arr artificial contrivance that promises to supply the loss of any particular part of the human body demands attention, and its merits should be fairly tested; but though it should not fulfil all the functions of the original organisation, which it could hardly be expected to do, or though it should not come up to the praises of its too confident inventor, or the expectations of those requiring its aid, still, if it confer a considerable amount of benefit, without any great discomfort in its application, we may fairly say that science has advanced a step in lending her aid to alleviate the ills to which flesh is heir.

I desire to call the attention of the profession, and those engaged in the aural department in particular, to a mechanical invention which has occupied my mind for some years, and has been tested in practice of late, though not by any means as extensively as I should wish. I would premise that two varieties of artificial tympana are used by aurists the medical profession in general, unfortunately, do not strive to advance our limited acquaintance of ear disease; or, still more unfortunately, do not endeavour to carry out the treatment as at present recommended by the best authorities; the consequence is, that aural surgery is rather in the background, and the sufferers fall daily into the hands of rapacious and lying quacks.

The first contrivance we know of is the moist cotton plan. Mr. Yearsley, of London, has the credit of being the first to publish it, though I have reason to believe it was known previous to his account; however, I do not want to detract in any degree from his merit. This plan consists in placing a very small bit of fine cotton wool moistened with some unctuous fluid in the position of the lost membrane, or where a perforation only exists, on it. It would take too long were I now to enter into all the particulars of the diseases causing this accident; it is described in various treatises on acoustic medicine. In certain cases of partial deafness, a great increase of hearing is the result ; in others, even when we do not accortain any epecial cause why it should not succeed, no benefit is derived; of course, a grent deal has been said on this subject, but I would merely romark that we are most likely to be successful where the perforation in the membrane is small, and where chronic disease has not disorganised the other complicated structures of the ear or its appendages; still, in very apparently hopeless cases of lost membrane, the moistened cotton, if properly placed in the site of the original, produces results more or less satisfactory. One of the adventages of this mode of treatment is, that the appliance is easily made by an intelligent patient, who may become more dexterous in hitting off the exact distance within the meatus than his adviser; but it requires to be frequently renewed, as the cotton becomes displaced and soiled, so as to render necessary a constant supply of cotton-wool and oil, or glycerine. It is also a question whether a plug of cotton filling up a large space in the meatus, and resembling more a wet sponge than a vibrating thin membrane, though it improves the hearing of a very deaf person, and is, therefore, of some use, and better than nothing, still causes the sounds conreyed to the ear to be heard indistinctly, and with a muffled accompaniment, which may be dispensed with by using a more perfect apparatus in connexion with the organ of hearing, and which I am now about to describe.

Several years since, during my pupilage with a distinguished oculist and aurist, it struck me that some more permanent structure, and one more resembling the real membrana tympani might be got up and placed in situ, instead of cotton. I was inclined to think that some matorial having the property of vibrating, and one resembling in its structure, thickness, and appearance, nature's contrivance, should, on principle, be best adapted for the purpose. Never having, till of late years, an opportunity of testing these tympana, the idea remained dormant in $\mathrm{mJ}$ mind for a long time; in the interim, Mr. Toynbee published his ideas, and an account of the peculiar contrivance he had invented. That the same investigation, leading to similar results, may be the work of two or more individuals, unknown to each other, is a well known fact. Some wonderful discoveries in the astronomical world have been brought to light by professors of different countries nearly at the sume time, without either being aware of the other's labours.

My first idea was to cut out a circular flat piece of some material, India rubler, gutta percha, or such like, and press it down to the site of the lost membrana tympani. In order to make it as like as possible to the real one, I coated its edges repeatedly with gutta percha dissolved in chloroform, so as to form a ring very analogous to the fibrous ring met with in the dissection of meatus and membrana tympani; now though this looks very well on paper, and was a close imitation of uature, I must confess, after patient and careful manipulation of it in the ears of patients, it did not equal my expectations at all. This was owing to two causes; first, if we recollect the anatomy of the meatus, we must remember that it is narrower in the centre than within, where the nembrana tympani is inserted, or without where it is of cousiderably greater diameter. Besides this impediment, there is another, specially intended by nature to impede the entrance of foreign bodies, namely, the curvature, which is thus described by a late author: "The meatus is ovoid in calibre externally, but becoming circular towards its distal end, and leading from the concha externally, at first a little forward and upwards, then backwards and inwards, and again turning downwards, forwards, and inwards to the membrana tympani, which separates it from the middle ear." Were it not for the narrowing at the centre, the curve could be easily overcome ; but as it is, they assist each other in rendering the proper insertion of any flat artificial membranes almost impossible. I always found flat bits of any material, whether cut circular or oval, double up, extremely difficult to place at the natural angle, and at the proper site; in addition, the hearing was not satisfactorily improved; this I accounted for by the fact, that the intended septum between the meatus and 
midllo car was not complete, wo the air freely passed around the crumpled membrane. Mr. Toynbee's contrivance is somernat of an improvement on this, as he adds to the pliable material a small circular plate of silver, or a ring, which prevents, in some measure, the crumpling, before alluded to; he intends that the India rubber, of which his membranes are constructed, should extend beyond the metal, and double up, so as to shield the sensitive walls of the meatus from the pressure of the metal.

I must confess I have had but little experience myself of his ingenious invention, but I have heard from surgeons that it did not give satisfaction in several cases coming under their notice; this might be owing to its being badly fitted, for which Mr. Toynbee is not to answer; again, in his invention, a wire is attached in the centre to facilitate its introduction and withdrawal, which it certainly does, as it is almost impossible to do either with a simple flat artificial membrane, the end of the wire stalk protrudes a little from the meatus. On the whole, my objection to this description of artificial membrane is, that it is by no means easily placed in situ, that vulcanised India rubber does not readily vibrate, and last, not least, that it does not form an air tight septum between the meatus and middle ear, as it should do, as the natural membrane does, and as I hope to show my contrivance may be made to do. In order to be easily understood, I shall give but a brief description of my fancied improvement upon all former contrivances, leaving it to time, the profession, and especially the aurists, to determine the relative merit of each. I do not want to overthrow or decry former appliances; I believe there will be cases found suited to each, and that the simple remedy, the original moist cotton of Mr. Yearsley, will be borne by some ears when nothing else will, at least for a time, till the irritability be subdued.

In the first place, my contrivance is a tube, very thin in texture, very pliant and durable in material, with a flat vibrating membrane at one end, the other extremity being open to admit the entrance of sonorous undulations. It is thus made: having accurately inspected the meatus, into which we desire to insert an artificial membrane, we must make a model of it in some hard timber (a cast is out of the question, - I frequently failed in the attempt); this model should be almost as perfect as a cast itself, though not too tight for the meatus; its end should be rather flat, and the circular edge nicely rounded off; the whole should be smooth and polished; this model, or, if we like to term it, timber cast, previously oiled, should be repeatedly dipped into a thin solution of gutta percha in chloroform till a film of sufficient thickness be formed to peel off in one unbroken piece; if the tympanal end of the timber model be of greater diameter than its centre (after the manner of the meatus itself, but this is not absolutely essential), it will be necessary to make a small slit in the side with a knife, but the incision should not approach within a quarter of an inch of the extremity, where the flat membranous part lies. This tube, if found of unequal thickness in any position, a slight coating of the solution may be applied so as to remedy the deficiency; if the timber cast or model has been properly made, and all successive steps accurately carried out, the membrane, when cut with a pair of scissors to the required length, will be found to fit the meatus pretty comfortably, and when oiled and coated with cerumen, to exclude the external air from the cavitas tympani. The tube itself should not be allowed to protrude, but should be cut obliquely, so as to lie entirely within the meatus. It easily adapts itself to the parts; the flat end lies at the proper angle in the site of the lost membrane, or on its remains. When it becomes advisable to clean its surface, it can be easily taken out by the patient with a small tweezers, washed, oiied, and reinserted; if found to fit, two or three of the same size should be made, and given to the patient, who should be taught how to use them. If there be a discharge, or fungoid growths, or obstructed Fnstachian tubes, or nervous impairment, or any other aural affection, these should be appropriately treated. Where the power of the auditory nerve is impaired, I am (in addition to usual treatment) in the habit of applying (in addition to usual treatmen of strychnia in either water within the meatus a solution of strychis in acid and spirit. or glycerine, dissolved by the aid of Why should it not I am inclined to think it does gool as it does those of the stime conjunctiva in functional amaueye, when dropped on the conjunctiva in fural disease our rosis? The more we bring to bear on aural and follow out the analogy, the more we shall advance aural surgery and increase our success in practice.

In conclusion, I must remark that though my contrivance for supplying an artificial membrand tympani is simple, still I do not expect that every person who tries to make or adjust them will succeed at first : it requires much make or adjust them will sucter fail as succeed in the attempt to construct a perfect membrane, as it is a difficult matter to construct a perfect mickness of the membranous tube. to hit upon the proper thickness requires to have a certain The solution of gutia pe as consistency and no more; it should be rather the allow of not to coat the timber model irregularly, and to allow of be allowed to dry perfectly : this must be repeated six or be allowed to dry perfectly : this or three days. The tube should not be taken off' when too thin in its substance, or it will tear; it should not be made too thick, or it will be hard, tough, and irritate the meatus; but it should be about as thick as very fine sheet gutta percha, or oil silk : it then is pliable, soft to the ear, and will easily vibrate when adjusted ; in short, the thinner it is made consistently with durability, the better.

As might be expected, a great deal depends on the nicety of the model; the timber requircs a great deal of carving, scraping, filing, and polishing; it must, moreover, be of the proner density, as soft woods will not make a smooth even model. The anatomy of each individual meatus must be strictly attended to. Without such attention being paid, I do not promise that any material benefit (and eveu at best artificial aids of any description are only very imperfect substitutes for the original) will be obtained. I hope I shall not be understood to say that I have discovered any specific cure for deafness.

Another point to be borne in mind is, that a foreign body of any kind should not be allowed to cause or keep up a discharge from the ear. I do not say that an artificial membrane may not be worn when only a very slight discharge exists; but it is better to get the ear into a healthy condition first; and even when everything is in as favourable a condition as possible, it should be remembered tha nated to adventitious aids all that on all extraneous matters, whether wooden legs, ivory teeth, or glass eyes, do not feel ccmfortable to tire wearer when first adopted.

It is not my intention to bring forward the details of cases at present. I would merely remark that I have tried my artificial membranes under two very opposite conditions: the one as unfavourable a case as it could be tried in, the deafness and disorganisation of ear being extreme; the other being the reverse, and a favourable subject to experiment on, part of the membrana tympani remaining, with, I believe, the ossicles, and the deafuess and condition of the ear not being bad. In the former, the artificial membrana tympani, contrary to expectation, increased in a slight though decided degree the power of hearing. In the latter, cousiderable benefit was (when last I saw the pationt) being derived from it. I generally first try the moist cotton plan to see whether the hearing is susceptible of any improvement; if so, then my artificial membrane is almost sure to answer even better; and even if the cotton does not afford the usual result, the thin gutta percha structure already described, being worn for a few days, the patient may, as in a case under my care, announce unexpectedly that he hears better.

The entire subject is still sub judice. I hope it will be investigated without the prejudice and malevolence which too often disgrace medical criticism.

14, Westbourno Place, Clifton, September 24th, 1853. 